\title{
Research on the Robot Application in View of Aging of Chinese Population
}

\author{
Xiaohong Cheng ${ }^{1, a}, \mathrm{Li} \mathrm{Qi}^{2, \mathrm{~b}}$ \\ ${ }^{1}$ Beijing Wuzi UniversityBeijing ,China,Beijing, 101149, China \\ ${ }^{2}$ Beijing Information Technology College,China,Beijing, 100015, China \\ aemail:bj201801@163.com, bemail:liq@bitc.edu.cn,
}

Keywords: Robot Application, Aging Markov Forecast.

\begin{abstract}
In view of the problem of the shortage of social labor force caused by the aging of our country's population, we predict the future population and the number of elderly people in China, and discuss the role of new robots in future industry, defense, medical care and service, Analysis of the existing problems, given the solution ideas.
\end{abstract}

\section{Introduction}

Since the advent of robots, especially industrial robots, has been accompanied by concerns about the unemployment of workers. However, the fact that the emergence of each new robot not only will not cause long-term, large-scale unemployment, but also to human beings have a new space for development, the relationship between people and the machine has become a partnership. The ever-renewing robot not only improves the living environment of human life, but also allows the human potential to develop to a higher level, so we need to further study the application of the robot. Especially in China increasingly into the aging society, the labor force population decline in the era of the robot will be more cannot be ignored.

\section{The status of the robot application.}

Robotics is a new synthetic discipline around mechanical engineering, electrical engineering, microelectronics engineering, computer engineering, engineering control, information sensing engineering, acoustic engineering, bionics, artificial intelligence engineering and other cutting-edge disciplines. Industrial robots are a branch of robotics, which represents the highest achievement of electromechanical integration. Since 1962, the United States has developed the first industrial robot, robot technology and robot products have developed rapidly, now it has become a automation tools used in flexible manufacturing system (FMS), automation factory (FA), and computer integrated manufacturing system (CIMS).

The robots have been widely used in electronic computers and network technology, they is increasingly changing the way human beings produce and live. After more than 40 years of development, robots have been applied in more and more areas. Industrial robots have been widely used in the manufacturing industry, especially in the automotive industry, Such as the rough manufacturing (stamping, die casting, forging, etc.), machining, welding, heat treatment, surface coating, assembly, testing and warehouse stacking operations. The robots have gradually replaced the manual operation. With the development of industrial robots is deeper, and wider and with the improvement of the intelligent level of the robot, The application of robots continues to expand from the automobile manufacturing industry to other manufacturing industries, and then to a variety of non-manufacturing industries such as mining robots, construction robots, hydropower systems maintenance and repair robots. In addition, there are more and more applications of robots in the fields of defense, military, medical and health services, such as unmanned reconnaissance aircraft, police robots, medical robots, domestic service robots and so on. 
Because science and technology continuous to develop, the further adoption of industrial robots cannot only improve the quality and quantity of products, but also improve the labor environment, reduce labor intensity, improve labor productivity, save raw material consumption and reduce production costs. Robots are playing an important role in improving the quality of human life.

\section{Chinese population forecast and population aging research}

Population aging is a product of economic and social development to a certain stage, involving the national economy, politics, culture, social construction and many other areas, is related to the people's livelihood and national sustainable development of major social problems and strategic issues. At present, China is in a new stage of building a well-off society in an all-round way and accelerating the socialist modernization. Is in a profound transformation of the system, the profound adjustment of the structure, the profound changes in society an important period, but also to deal with the aging population is very critical period. At present, China's population aging situation has been very grim. Faced with the aging of the population and the total population of excessive pressure.

After the founding of our country population growth soon, in 1949 China's population is only 542 million, by 2000 our population has grown to 1.2 billion. After the reform and opening up, although the implementation of a strong family planning policy to control population growth, but due to the growth of the population base of inertia, the early 80s growth rate is still fast. With the passage of time, the population growth rate slowed down. In the 1890s to 2017, our population achieved the goal of low population growth. But a more realistic problem in front of, that is, the rapid aging of our population. In accordance with international standards, China has been in an aging society, and entered a period of rapid development. At present, China's population aged over 6 has reached 144 million, accounting for $1 \%$ of the total population, and will increase at an average annual rate of $3 \%$.

We consider the population of different age groups over the years, considering the urban and rural gender ratio, birth rate, mortality and domestic population migration and other factors, the establishment of population transfer matrix, combined with the curve fitting and other statistical methods, the establishment of the population forecast Marco Model. According to the model, Chinese population will reach its peak in 2030, about 1.44 billion, reaching 1.41 billion by 2050 . Forecast data also show that Chinese elderly population in 2021 will reach 170 million people, accounting for about $12.8 \%$ of the total population; 2022 will reach 250 million, accounting for about $17.2 \%$ of the total population. From 21 to 22 years, Chinese elderly population to a net increase of 100 million, and then into the high-speed development stage, into the severe aging, predicted by 2050, Chinese aging population will account for about $50 \%$ of the total population, Chinese population aging The problem is very serious.

\section{The development of the robot application based on Chinese population aging}

With Chinese aging is further serious, the application of robots will be the attention of all parties. However, there are still many serious problems in the research and application of domestic robots, and we must take corresponding effective measures against these problems.

(A) Domestic patent applications in foreign countries is still very little technology, the lack of core technology in the field of robotics is still very serious. In this regard, China must learn from Japan, because in the industrial robot several key technical areas, Japan's patents accounted for nearly $70 \%$ of the world; Japan in the harmonic reducer, RV reducer, welding clamp, weld tracking patent More than half of the global total, in these areas, the Chinese patent is only about $10 \%$; In addition, almost all of the key technical areas, with the largest number of enterprises from Japan. Therefore, China should strengthen the direction of the robot teaching and research strength, and actively independent research and development of core technology, the country has a number of enterprises in this regard to achieve results, the state should focus on fostering these enterprises, and launched the support of local industry. 
(B) The country currently holds a large number of production workers, industrial robots use less, the robot density is very low. Industrial robot density and production efficiency, product quality and performance are positively related to the industry is an important indicator of high-end. As the manufacturing industry is the use of more extensive robot industry, so the manufacturing industry, for example, South Korea, Japan and Germany, industrial robot density were 487,323 and 282 / million workers, the highest in the world; and China's industrial robot density 14 units / million workers. Obviously, China has a lot of space can improve the density of industrial robots to improve the cost of manufactured goods, thereby enhancing the quality of our pillar industry development and competitiveness of the important path. With the arrival of China's aging society, the introduction of more efficient industrial robots in the production line to replace the labor force is an important measure to solve the labor shortage.

(C) The impact of the use of the robot on the labor market also includes changing the employment structure, in the case of insufficient labor, can fill the positions of human workers. After the introduction of industrial robots, the production process and management will also be adaptive adjustment, high strength, low skill, and even some skilled workers will be replaced by robots, will increase the knowledge and skills of staff needs, The corresponding increase in the production of service industry practitioners increased, in short, the introduction of the robot will lead to high-end employment structure. Not only to create more jobs, to ease the employment pressure, but also to relax the labor force population age limit, more 60-70 years of age from the aging population to the labor force population, to solve the problem of social aging to help.

It is important to emphasize that the large number of robots currently used in China is mainly based on the second generation of robots, so the impact is mainly reflected in the replacement of low-end skilled workers, with the increase in the number of intelligent robots installed, the future will be the population employment structure Causing greater impact.

In a nutshell, in order to cope with the upcoming aging society, China must take a step forward in the application of new robots. Our government not only pays attention to the industrial robot applications in the manufacturing, but also to the application of robots in the fields of defense, military, medical and health services. We must actively cultivate the relevant personnel of the reserve, organize and train the team of robot research and development, focus on fostering the development and production of the top departments. we must establish several engineering companies for the quantity production of industrial robots and implementation of robot applications. so Robot production and application realize industrialization and group direction. Grasping the opportunities and meeting the challenges, we will expand the application of the robot collar, and actively open up the domestic robot market, to deal with the advent of aging society, to maintain China's stable and rapid development momentum.

\section{Acknowledgements}

Beijing Key Laboratory(NO:BZ0211) and Beijing Intelligent Logistics System Collaborative Innovation Center.

\section{References}

[1]Wang Haixia, Li Zhihong, Wu Qingfeng. Application and development of industrial robots in manufacturing [J]. mechatronics engineering technology, 2015,10:112 114.

[2]Cheng Qiliang, Yu Sheng, Wang Bo, Li Huanhuan, Zhang Yanfang. Summary of research on palletizing robot in industrial production [J]. mechatronics technology, 2016,02:135, 138.

[3]Zhao Xiaofei, Guo Lifeng. Application of industrial robots in mechanical processing [J]. mechanical research and application, 2015,03:113 115117. 
[4]Xie Cunxi, Guo Chisheng, Chen Xinghai. Method of improving assembly accuracy on automatic assembly line [J]. Journal of South China University of Technology (NATURAL SCIENCE), 2014 (04): 41-45.

[5]Zheng Shixiong, Liu Guixiong, Yan Hua. Application of robot vision in automatic assembly line [J]. optics and precision engineering, 2013 (01): 91-95. 